\title{
DISCURSOS SOBRE A INFÂNCIA EM FORMAÇÃO INICIAL DE PROFESSORES - PORTUGAL NAS ÚLTIMAS DÉCADAS
}

\author{
SPEECHES ON CHILDHOOD IN EARLY TEACHER \\ TRAINING - PORTUGAL IN THE LAST DECADES \\ DISCOURS SUR L'ENFANCE DANS LA FORMATION INITIALE \\ DE MAÎTRES - PORTUGAL DANS LES DERNIÈRES DÉCENNIES \\ DISCURSOS ACERCA DE LA INFANCIA EN LA FORMACIÓN INICIAL \\ DE PROFESORES - PORTUGAL EN LAS ÚLTIMAS DÉCADAS
}

Fátima Pereira*

\section{RESUMO}

O texto aborda algumas dimensões de um estudo realizado no âmbito de uma tese de doutoramento em Ciências da Educação que pretendeu conhecer e compreender as concepçōes sobre a infância que se exprimem na - ou se relacionam com a - formação inicial de professores do $1^{\circ} \mathrm{CEB}$, em Portugal desde Abril de 1974. Configurou-se uma problematização multirreferencial em torno da gestão discursiva da crise da infância moderna, da profissionalidade docente e da instituição escolar em tempos de modernidade tardia. A dimensão morfológica do estudo constituiu-se pela configuração e o mapeamento social de narrativas sobre a infância que se identificaram na interpretação dos campos discursivos produzidos na análise. Identificaram-se, ainda, narrativas sobre a profissionalidade docente e sobre a educação escolar com as quais as narrativas sobre a infância se articulam de forma particular. Realçam-se os resultados que dizem respeito às transformaçôes verificadas nos discursos, no período em análise, e ao mapeamento social das narrativas da infância.

Palavras-chave: Currículo. $1^{\circ}$ ciclo do ensino básico. Formação inicial de professores. Narrativa. Mapeamento social.

* Doutora. Professora da Faculdade de Psicologia e de Ciências da Educação da Universidade do Porto, Portugal (fpereira@fpce.up.pt). A grafia é a utilizada em Portugal. 


\section{INTRODUÇÃO}

Ao longo do estudo (PEREIRA, 2007), que aqui se aborda de forma parcial, procurámos desenvolver uma reflexão sobre a infância, a sua educação escolar e as relações que a profissionalidade docente com ela estabelece, evocando discursos que se relacionam com a emergência e a implementação do projecto sociocultural, político e económico da modernidade e com o seu declínio (ou a sua reconfiguração), focalizando-nos nos discursos implicados na institucionalização que o fundamentou e nos discursos que pretendem narrar e compreender as transformações das subjectividades e das sociabilidades que caracterizam a modernidade tardia e que têm impacto nos mundos da vida da infância, na instituição escolar e na profissionalidade docente.

$\mathrm{O}$ estudo pretendeu conhecer e compreender as concepções sobre a infância que se exprimem na - ou se relacionam com a - formação inicial de professores do $1^{\circ} \mathrm{CEB}$, em Portugal desde Abril de 1974, pressupondo que elas pudessem indiciar os sentidos e os significados do governo da infância na instituição escolar e, assim, esclarecer dimensões sociais mais latas: a reinstitucionalização da infância e o lugar social que se lhe configura; a profissionalidade docente; e as relaçôes da crise da instituição escolar com a crise social da modernidade.

A gestão discursiva da modernidade, especificamente sobre a infância, a profissionalidade docente e a instituição escolar, e das suas crises, em diferentes campos sociais, constituiu uma dimensão conceptual que atravessou todo o estudo e que foi assumindo configuraçôes distintas e caleidoscópicas de acordo com o campo a que se referia, evidenciando significados que constituíam constelações conceptuais particulares. A linguagem é, por isso, um domínio de reflexão teórica que integramos neste texto.

Procura-se, aqui, recuperar parte da reflexão desenvolvida no estudo, abordando-se sucintamente algumas das concepções que constituem a problemática e a metodologia desenvolvida e apresentando-se alguns dos resultados, a sua interpretação e uma reflexão prospectiva sobre a conceptualização da infância em formação inicial de professores.

\section{O DECLÍNIO DAS INSTITUIÇÕES MODERNAS: A INFÂNCIA, A EDUCAÇÃO ESCOLAR E A PROFISSIONALIDADE DOCENTE}

Nos últimos dois séculos, a infância foi construída e reconstruída, em grande medida, através de um trabalho de síntese entre poder e conhecimento: o discurso profissional e os saberes especializados. Scraton (1997, p. 16) designa por "profissionalização da infância" a emergência e o desenvolvimento de "especialismos discretos - cada um com o seu conhecimento e poder" que têm um mandato especializado e específico para manter e reproduzir instituiçôes que penetram e regulam o mundo social e subjectivo da 
infância. $\mathrm{O}$ trabalho de cuidar e instruir as crianças integrou-se numa rede extensa de actividades profissionais institucionalizadas, na qual cada uma desenvolveu um corpo próprio de conhecimento especializado e de técnicas que expressam a sua autoridade e especificidade profissionais (ibid.).

A emergência da ideia de infância moderna associa-se intrinsecamente à emergência da modernidade e à consolidação das instituiçōes modernas, com especial relevância para a família e a instituição escolar (ARIĖS, 1978). A infância, podendo ser compreendida como um objecto socialmente construído - que se refere a um estatuto social com fronteiras instáveis e que determinam os padrōes de conduta, vinculando-se a um contexto cultural específico (JENKS, 2002) -, não constitui, no entanto, apenas, uma construção social instituída em formas estruturais que a constrangem; ela resulta de processos dialécticos que a colocam numa rede de relações sociais dos adultos com as crianças e destas entre si, que integra formaçôes ontológicas alicerçadas em sistemas de interacção social que afectam a vida das crianças e no impacto da sua natureza e acção específicas. Assim, reflectir sobre a infância é um desígnio complexo que articula diferentes entidades sociais, diversos campos epistemológicos e concepções ontológicas conflituais.

As transformaçōes que têm instabilizado a modernidade têm também afectado a conceptualização sobre a infância, a configuração do seu lugar social e a sua institucionalização. A ciência moderna instituiu-se como o campo social mais determinante na configuração da ideia de infância moderna, o que foi reforçado pela sua intrínseca associação à institucionalização escolar. A subjectivação escolar fundamentou-se em dispositivos cognitivos, perspectivas morais e concepçôes éticas que focalizaram na infância as possibilidades da sua realização. Os dispositivos cognitivos foram elaborados, essencialmente, pela ciência moderna, que não se limitou a disponibilizar os referenciais teóricos e metodológicos para a prática educativa, mas determinou também os imperativos morais da educação escolar da infância.

A crise da infância, na modernidade tardia, relaciona-se, entre outras dimensões, com a sua globalização, que Sarmento (2002) refere como sendo responsável pela mudança e pela pluralização das suas identidades. $\mathrm{O}$ autor considera a globalização da infância como resultante de processos políticos, económicos, culturais e sociais e como actuando de modo polarizado entre a difusão da ideia da defesa dos interesses da criança e da sua definição e as consequências para a geração da infância das desigualdades promovidas pela globalização económica. Os efeitos dessa polaridade são complexos e antinómicos e tornam incerta a identidade contemporânea da infância, que não só exprime a pluralização de identidades, mas também resulta de processos de mudança identitária relativos a uma reinstitucionalização da infância (ibid.). Nos processos de reinstitucionalização da infância, o declínio da instituição escolar moderna (DUBET, 2002), os sistemas conceptuais que se criam na sua administração e as racionalidades que os matriciam são fundamentais para o esclarecimento das identidades que aí se configuram. 
Não sendo sensato imputar à Escola todas as responsabilidades no incumprimento sistemático das promessas de igualdade das democracias ocidentais, não podemos deixar de considerar que a escolarização está profundamente implicada no actual contexto social e económico de instabilidade, incerteza e conflitualidade. Perante a ruptura das certezas científicas, morais e ideológicas que sustentaram a consolidação dos estados modernos, fundamentada na solidez das suas instituições sociais, a Escola imergiu numa profunda crise, para a qual não tem conseguido encontrar respostas adequadas.

A institucionalização moderna realizou-se com base num programa institucional que define um modo de socialização, um processo social que transforma os valores e os princípios em acção e em subjectividade, que pela sua estabilidade produz tipos-ideais (ibid.). Esse programa fundamentou-se nos ideais da modernidade, que induziram a crença de que as instituições eram simultaneamente habilitantes e constrangedoras, inculcando normas que conformam o indivíduo, mas também o tornam livre e autónomo. A esta crença associava-se a ideia de que o trabalho de socialização, nas instituições, devido à dimensão axiológica que o caracteriza, constituía uma vocação; o profissionalismo mais não era do que a materialização e a dimensão técnica dessa vocação, e a legitimidade que o fundamentava sustentava-se numa autoridade carismática, outorgada pela adesão a princípios e a valores universais, configuradores de uma legitimidade sagrada (ibid.). Mas a sacralização das instituições modernas já não é mais possível, num tempo de pluralização das lógicas e princípios de acção e de justiça, de confronto entre valores contraditórios e de emergência de racionalidades compósitas; a impossibilidade de unificar essas formações discursivas numa retórica universalista desoculta tensões incontornáveis e produtoras de novos processos de socialização e de subjectivação mais contingentes e, por isso, sujeitos a arbitrariedades de tipo particular.

O programa institucional dá então sinais de um declínio irreversível e heterogéneo, traduzido em sucessivas crises que o transfiguram, mantendo alguns traços originais e constituindo outros, nem sempre articulados pela lógica racionalista da modernidade, mas que a fracturam. A ilusão sobre a homogeneidade, a coerência racional, a justiça e a justeza dos sistemas sociais modernos desfaz-se perante as reivindicações individualistas e particularistas das lógicas de acção localizadas e a constatação sobre a existência de um mundo globalizado que evidencia o drama humano da hegemonização cultural e económica da racionalidade ocidental moderna, traduzido no aumento das desigualdades sociais a nível planetário, na emergência de fundamentalismos étnicos e religiosos e na ameaça generalizada ao equilíbrio ecológico mundial. Os conflitos sociais que daí resultam tornam-se exacerbados, pela incapacidade de criação de sistemas ideológicos coerentes e unificados, que outrora era assegurada pelas instituições modernas. As instituições tornam-se mais flexíveis e contingentes, possibilitando a reemergência e a afirmação do sujeito autónomo, simultaneamente actor e autor, e alterando as representaçōes sobre a sociedade. 
A crise da educação escolar é também a crise da profissionalidade docente, e as narrativas que se produzem na sua gestão são parte essencial da reinstitucionalização da infância. A finalidade normativo-socializadora das práticas educativas escolares tem sido determinante na formação das racionalidades que orientam a acção dos professores, os quais - enquanto socializadores legítimos e legitimados pela instituição escolar, dotados de um saber especializado no cuidar e formar a infância - contribuem, incontornavelmente, para a determinação das condiçôes sociais, presentes e futuras, condicionadoras das formas de vida das crianças e das suas identidades. Mas as crianças manifestam, cada vez mais, a capacidade de produção de si próprias, e a escola constitui um universo político no qual desenvolvem capacidades de aceitação e de negociação das regras impostas pelos adultos e de invenção de novas regras, assumindo opiniōes e decisōes sobre as suas dimensōes de justiça que questionam as funçōes socializadoras tradicionais (RAYOU, 1999). Essa realidade confronta as racionalidades profissionais dos professores e interfere na sua acção e na interpretação que realizam sobre o sentido ético do seu trabalho.

A formação inicial de professores constitui um locus institucional de convergência das novas - ou das velhas, recontextualizadas - narrativas sobre a educação escolar da infância, o estatuto ontológico, o lugar social e a natureza de se ser criança e representa, por isso, o cerne da germinação da reinstitucionalização escolar da infância.

\section{INFÂNCIA E EDUCAÇÃO ESCOLAR EM PORTUGAL}

$\mathrm{O}$ ensino primário (actual 1 ${ }^{\circ} \mathrm{CEB}$ ) em Portugal tem características particulares que lhe conferem um lugar próprio nos discursos que visam regular o sistema de ensino. Pela sua historicidade, ele constitui a instituição mais instrumentalizada, desde a emergência da modernidade, nos desígnios sociopolíticos de transformação social ou da sua reprodução, e foi o mais fiel representante da "Escola Salazarista». Essa condição atribui especificidades à identidade profissional dos professores do ensino primário, tornando-a cativa de representações que a condicionam a uma regulação centralista e lhe retiram autonomia na definição das dimensões da sua construção. Em Portugal, desde Abril de 1974, o ensino primário não escapou à instabilização da instituição escolar e à complexificação e intensificação dos contextos sociais que tendeu a deslegitimar o lugar social da Escola e a produzir mandatos sociais plurais e contraditórios que contribuem para agudizar os sintomas da sua crise. Na procura de responder aos diversos mandatos sociais que se demandam à educação escolar, a regulação do ensino primário realizou-se pela sua submissão a diversas reformas curriculares que, no entanto, não produziram os efeitos que a sua retórica vaticinava.

A análise da incapacidade das reformas educativas em gerar as mudanças que anunciam foi realizada no âmbito de diversos estudos que, ora focalizam essa incapacidade no facto de as reformas se implementarem segundo uma racionalidade centralista e 
administrativa que não tem em conta as características das condições e dos actores sociais particulares que as deverão viabilizar, ora a focalizam numa tendência para a resistência à mudança por parte dos professores. Pensamos, no entanto, que essas duas perspectivas não se excluem mutuamente e, pelo contrário, estão intrinsecamente relacionadas; a transformação educativa relaciona-se com processos profundamente complexos que integram os interesses e as características dos actores sociais nela implicados e as lógicas e as racionalidades que caracterizam as formas de intervenção na instituição escolar, relacionando-se mais com as formas de vida que nela se criam do que com a pretensa qualidade das propostas ou com a adequação dos dispositivos técnicos que as acompanham (PEREIRA, 2001).

No período em que focalizámos o nosso estudo, o ensino primário foi objecto de várias reformas curriculares que, no entanto, não produziram as mudanças que anunciavam. Mas, apesar disso, as transformações são inevitáveis, mesmo não obedecendo às lógicas e às racionalidades que relativamente a elas centralmente se determina. A Escola, apesar dos esforços da modernidade em a manter «fora do mundo», está bem no seu cerne, e as conturbações que afectam a economia, a política e a sociedade afectam também a vida das famílias e a das crianças, com implicações nas formas de relação que estas mantêm com a instituição escolar. Essas mudanças integram-se nos quotidianos escolares para os perturbar, instabilizando as convenções sociais escolares e os dispositivos institucionais de regulação da infância. Não obedecendo às prescrições reguladoras do estado, as mudanças na instituição escolar revelam-se contingentes e subjectivas, sem visibilidade social e difíceis de compreender e de gerir.

A formação inicial de professores do $1^{\circ} \mathrm{CEB}$ articula-se, ainda que indirectamente, com as transformações no $1^{\circ} \mathrm{CEB}$, e em Portugal tem sofrido profundas mudanças em diferentes dimensões. Partimos para o estudo com a intenção de conhecer e compreender de que forma essas mudanças tiveram implicações na conceptualização sobre a infância e a sua educação escolar, contextualizando essa intenção numa problemática mais ampla que considerava as relações entre a crise da modernidade - especificamente das suas instituiçôes -, e dos modelos de humanidade e de sociedade que a sustentaram, e a conceptualização da infância. Pressupúnhamos que a conceptualização sobre a infância na modernidade se relacionou com desígnios civilizacionais de construção das sociedades ocidentais e que a instituição escolar assumiu aí um lugar determinante. As transformaçôes socioculturais, políticas e económicas e as metamorfoses da ciência moderna que com elas se articulam, que têm perturbado a modernidade, têm afectado também a conceptualização da infância. 


\section{O LUGAR DA LINGUAGEM}

O declínio das instituições modernas tem originado transformaçōes nos discursos políticos e científicos que as sustentaram e nas ideologias que configuravam. Essas transformações têm-se evidenciado nas ideologias educativas que caracterizam a situação da instituição escolar portuguesa desde Abril de 1974 e nos discursos que pretenderam legitimar as sucessivas reformas educativas, com impacto na formação inicial de professores e na conceptualização da infância. Esses discursos definem novos lugares sociais para a infância e induzem a sua reinstitucionalização; eles condicionam, ainda, as possibilidades de transformação da profissionalidade docente e da instituição escolar.

Como refere Foucault (2004/1969, p. 55), o discurso constitui "práticas que formam sistematicamente os objectos de que falam" e, por isso, os discursos têm impacto na constituição do mundo social, designadamente dos mundos da vida da infância e das suas possibilidades de afirmação no espaço escolar. A linguagem é uma dimensão fundamental na produção e na reprodução de significados que condicionam as interacçôes e a constituição das identidades, que se relacionam com formas de poder social e são por elas condicionados.

O mundo da vida institui-se pelas acções, pelos actos de fala e pelas interacções linguisticamente mediadas e, por isso, a linguagem é parte integrante da sua formação (HABERMAS, 2002). A sociedade enquanto mundo da vida simbolicamente estruturado carece para o seu desenvolvimento e reprodução da mediação realizada pela acção comunicativa, aquela que se fundamenta no uso da linguagem orientado para o entendimento, isto é, para a partilha de interpretações sobre o mundo.

As práticas comunicativas nas quais se integra a linguagem fundamentam-se em reservas de conhecimento que se consolidam por processos de interpretação e transformação em normas e valores e têm impacto, por processos de socialização, na formação de atitudes, percepções e identidades (ibid.).

A linguagem tem uma dimensão dialéctica e interactiva que a situa no espaço-tempo da mediação sociocultural e da formação das subjectividades. A heterogeneidade é constitutiva da linguagem que se caracteriza pelo dialogismo - o confronto entre diferentes vozes e sistemas de valores que integram uma diversidade de percepções e de interpretações sobre o mundo que condiciona o sentido do discurso (BAKHTIN, 1992). Por isso, o discurso nunca é individual, porque se define entre o eu, o tu e o mundo, construindo-se numa "polifonia de vozes", numa interdiscursividade que o transforma numa entidade híbrida, simultaneamente social e individual, composta por discursos concorrenciais e de sentidos eventualmente conflituais; ele também nunca é temporalmente estritamente situado, uma vez que pelo interdiscurso define relações com o passado, o presente e o futuro. 
Os dispositivos de regulação discursiva da instituição escolar não são, por isso, meramente retóricos, implicando-se no fazer e no ser dos quotidianos institucionais, e em Portugal têm sofrido mudanças que pretendem legitimar a produção de medidas legislativas, em diferentes domínios do campo educativo, que visam a adaptação institucional às transformações socioculturais e económicas que se têm verificado e com as quais se articulam discursos políticos e ideológicos específicos. Essas medidas tiveram implicações na organização e nos conteúdos da formação inicial de professores do $1^{\circ} \mathrm{CEB}$. Por outro lado, a deslegitimação das grandes narrativas da ciência moderna e a dessacralização da instituição escolar tiveram impacto nas concepçôes que se determinam como essenciais para a profissionalização desses docentes. Dessas concepções, as que se referem à infância são determinantes para se compreenderem as mudanças nas perspectivas epistemológicas sobre a infância que indiciam um novo modo de as governar e de as institucionalizar.

\section{A DIMENSÃO METODOLÓGICA DO ESTUDO}

Fundamentando-nos em vários autores, designadamente, De Bruyne, Herman e Schoutheete (1991) e Lessard-Hébert, Goyette e Boutin (1994), considerámos a metodologia na acepção lata que a caracteriza como uma prática social que pretende constituir-se numa praxiologia da produção dos objectos científicos, integradora das diferentes dimensões da cientificidade: a epistemológica, a teórica, a técnica e a morfológica. Por praxiologia designamos uma prática social eticamente significativa e teoricamente informada, rejeitando o sentido aristotélico que a encerra em si própria (e nos fins que lhe são intrínsecos) e salientando o seu carácter cognoscitivo e transformador das situaçôes sobre as quais incide a sua acção e dos actores que as levam a cabo.

No pólo epistemológico privilegiámos uma perspectiva dialéctica-hermenêutica que configurou uma problemática multirreferencial em torno da gestão discursiva das crises da infância moderna, da profissionalidade docente e da instituição escolar. O pólo teórico foi constituído por um mapa de ideias e de conceitos, designadamente sobre: a modernidade, a institucionalização e a subjectivação; o campo epistemológico da infância, a educação escolar das crianças e os discursos em educação; infância e educação escolar em Portugal: o lugar da formação inicial de professores; mundo social, linguagem, discursos e formas de vida.

O campo empírico do estudo foi definido no domínio da formação inicial de professores do $1^{\circ} \mathrm{CEB}$ e abrangeu os diferentes tipos de curso realizados desde Abril de 1974 até à actualidade, em escolas de ensino público e privado: curso de magistério primário; curso de bacharelato em 10 CEB; curso de professor do ensino básico; curso de licenciatura em $1^{\circ} \mathrm{CEB}$. O corpus foi constituído por discursos, directa ou indirectamente, relacionados com a infância, relativos aos diferentes tipos de formação e inscritos em 
planos de estudos e respectivos programas das disciplinas, relatórios de estágio e narrativas biográficas de professoras. Os discursos analisados, enquanto entidades de linguagem, foram perspectivados como uma forma de prática social que reproduz e transforma saberes, identidades e relações sociais, sendo constituídos concomitantemente por outras práticas sociais com as quais estabelecem relaçôes dialécticas. Os discursos foram objecto de análise de conteúdo.

O pólo morfológico constituiu-se pela identificação e o mapeamento de narrativas sobre a infância, a educação escolar e a profissionalidade docente.

\section{ALGUNS RESULTADOS DO ESTUDO}

Os três campos discursivos - cada um representando as concepçôes identificadas em cada forma de discurso: currículo formal (planos de estudos e programas das disciplinas), relatórios de estágio ou narrativas biográficas - que se produziram na análise revelaram a natureza contraditória, complexa e conflitual da narração sobre a infância nos discursos em formação inicial de professores.

\section{Os planos de estudos}

A comparação da análise dos planos de estudos dos diferentes tipos de formação inicial possibilitou compreender que, desde Abril de 1974, a área de "Ciências da educação" tem adquirido uma importância crescente no currículo, ocupando nos cursos de licenciatura a posição de área mais expressiva. A área de "Pedagogia" tem sofrido alterações que lhe retiraram a dimensão teórica que a caracterizava nos cursos de magistério primário e diminuíram a importância da sua dimensão prática. A área de "Didáctica" tem conquistado um lugar cada vez mais expressivo no currículo, e a área de "Expressão e comunicação", com excepção para a primeira metade da década de 1990, tem sempre uma forte centralidade no currículo. A psicologia, nos cursos de licenciatura, perde a hegemonia que a caracterizou nos cursos anteriores, equiparando-se às restantes disciplinas que formam a área de "Ciências da educação".

\section{Os programas das disciplinas}

A comparação da análise dos programas das disciplinas dos diversos planos de estudos revela que a conceptualização da infância na formação inicial de professores se tem complexificado, evidenciando-se nos cursos mais recentes mais ambígua e contraditória; a criança é o centro da acção educativa nos cursos de magistério primário e de bacharelato em $1^{\circ} \mathrm{CEB}$, deslocando-se essa centralidade para o professor e para o contexto educativo nos cursos de $\mathrm{PEB}$ e de licenciatura em $1^{\circ} \mathrm{CEB}$, nos quais a psicologia deixa de ser o domínio disciplinar mais determinante para se reflectir e configurar a educação 
escolar da infância, ocupando a teoria do currículo esse lugar. A complexificação e a pluridimensionalidade que se identificam, nos cursos mais recentes, nas concepções sobre a infância, identificam-se, também, relativamente à conceptualização do adulto, evidenciando-se uma intensificação da dimensão reflexiva e problematizadora na caracterização do adulto, integrando-se a perspectiva do sujeito ético numa antropologia do projecto e numa cidadania da responsabilidade e da participação. As concepções sobre a educação escolar sofrem transformações relevantes ao longo do período analisado: desde a sua conceptualização enquanto meio primordial para a construção do socialismo e para a mudança social, no período pós- 25 de Abril, à sua recente focalização na acção educativa imediata, relativamente à formação e à inclusão escolar dos alunos, e na subjectivação no sentido da constituição de cidadãos emancipados, autónomos e intermulticulturais, capazes de gerir as suas vidas num mundo complexo e global.

\section{Os relatórios de estágio}

A comparação da análise dos relatórios de estágio dos diferentes tipos de formação revelou-nos que, de um modo global, os discursos que narram a infância e a sua educação escolar se complexificam numa relação directa com a sua academização, isto é, com a sua inserção em cursos que conferem uma habilitação académica superior. Realça-se ainda: uma descentração da problemática da subjectivação integradora - inscrita nos cursos de magistério primário - para a problemática do sujeito reflexivo e da sua integração social pelo exercício da cidadania, que se evidencia nos cursos de licenciatura em $1^{\circ}$ CEB; uma diversificação, nos cursos mais recentes, dos tipos de autoridade e das formas de poder, relacionada com a emergência de uma disciplina mais reguladora do que controladora e que responsabiliza as crianças pelos seus comportamentos, atitudes e aprendizagem; e uma progressiva permeabilidade entre as concepçôes de aluno e as de criança, que culmina nos cursos mais recentes numa conceptualização do aluno que integra as concepçõos de criança redimensionando-as por relação com a escolarização.

\section{As narrativas biográficas}

A comparação da análise das narrativas biográficas revelou-nos que a arqueologia das "Concepçôes de infância" se constitui sempre nas "Memórias de infância" e nos "Saberes e competências" da "Formação inicial", podendo ainda constituir-se: na "Identidade profissional", no que diz respeito à "Atitude profissional", à "Vocação" e aos "Princípios e valores"; na "Ética socioeducativa" e nas "Motivaçôes e (des)ilusōes" da "Formação inicial"; e na "Relação", na "Ontologia" e na "Moral e a ética" da "Prática socioeducativa". A "Ontologia" e a "Subjectividade" das "Concepções de infância" sofrem alteraçōes por relação com os tipos de formação em que se inscrevem as narrativas biográficas, revelando-se frágeis e ameaçadas, nas que dizem respeito ao curso de magistério primário do 
$1^{\circ}$ subtipo (período pós 25 de Abril), e contraditórias, incompreensíveis e surpreendentes nas que se inscrevem nos cursos de licenciatura em $1^{\circ} \mathrm{CEB}$, apesar de serem sempre perspectivadas como estando marcadas pela heterogeneidade cultural e subjectiva e situarem a criança na condição de formação para um futuro lugar social como adulto.

A arqueologia das "Concepçôes de aluno" constitui-se sempre nas "Memórias de infância", nos "Saberes e competências" da "Formação inicial" e na "Relação" da "Prática socioeducativa". A "Subjectividade" nas "Concepçôes de aluno", apesar de revelar algumas especificidades relativas aos tipos de formação inicial em que se inscrevem as narrativas biográficas, revela-se essencialmente plural e ambígua em todos os tipos. As "Concepções de aluno" não se restringem ao domínio da aprendizagem, focalizando-se sobretudo na dimensão moral e social da educação escolar. O aluno é sempre o sujeito-objecto da educação escolar, mas nos cursos de licenciatura em $1^{\circ} \mathrm{CEB}$ ele é sobretudo o seu sujeito. $\mathrm{Na}$ relação das concepções de criança e de aluno constata-se, nas narrativas inscritas nos cursos de bacharelato em $1^{\circ} \mathrm{CEB}$ e nos de licenciatura em $1^{\circ} \mathrm{CEB}$, uma semântica similar à que se identificou nos relatórios de estágio dos cursos mais recentes, na qual as concepções de aluno consideram que este integra as características da criança, mas as extrapola em função das competências que desenvolve enquanto aluno.

As regularidades mais marcantes no que diz respeito à "Formação inicial" relacionam-se: com a relevância que lhe é atribuída em todas as narrativas (com uma única excepção); com uma motivação para a escolha da profissão justificada por uma espécie de vocação emergente na infância e que se consolidou pela relação estabelecida com as crianças; e com a referência à psicologia do desenvolvimento (as concepçôes da epistemologia genética de Piaget) como a disciplina mais relevante para a prática profissional. A "Ética socioeducativa" induzida pela "Formação inicial" revela um desvio da centração na criança, nos cursos de magistério primário e de bacharelato em $1^{\circ} \mathrm{CEB}$, para a centração no trabalho pedagógico, no profissionalismo e na protecção da pessoa do professor nos cursos de PEB e de licenciatura em $1^{\circ} \mathrm{CEB}$.

A "Prática socioeducativa" caracteriza-se por uma subjectivação focalizada na formação do cidadão, em todos os tipos de formação, com excepção para o curso de magistério primário do $1^{\circ}$ subtipo; a sua "Ontologia" é narrada como problemática e intrinsecamente contraditória e revela-nos uma infância dicotomizada entre as formas de vida escolares e as formas de vida extra-escolares, privilegiando as primeiras a antropologia do projecto, nos casos em que a formação inicial foi realizada em cursos do ensino superior. 


\section{DIMENSÕES DE INTERPRETAÇÃO}

\section{As narrativas da infância}

A heterogeneidade dos discursos sobre a infância identificada nos campos discursivos não nos permitiu definir um único articulado de narração sobre a infância em cada tipo de formação ou forma de discurso específicos. No entanto, perspectivava-se a possibilidade de relacionar determinadas concepções segundo racionalidades que as constituíam em narrativas que se inscreviam simultaneamente em diferentes tipos de formação ou formas de discurso, o que as transformava numa rede de referencialização da conceptualização sobre a infância. $\mathrm{O}$ trabalho de constituição dessas narrativas revelou que elas se relacionavam com narrativas sobre a profissionalidade docente e sobre a educação escolar ${ }^{2}$ que também configurámos.

Identificámos cinco narrativas sobre a infância: "infância como projecto social", "infância com lugar próprio", "infância idílica”, "infância produtiva” e "infância em crise". Cada uma destas narrativas foi constituída por formações particulares relativamente a diferentes dimensões: a conceptual, a ideológica, a cultural, a ontológica, a ética e a política, sendo a expressão de cada uma delas mais intensa nuns tipos de formação e formas de discurso do que noutros, apesar de circularem entre eles.

A narrativa da "infância como projecto social" realça o lugar social que se tem atribuído à infância enquanto foco de utopias civilizacionais e configuradoras de modelos de sociedade e de humanidade específicos, mas também de utopias particulares que idealizam modelos alternativos; ela é informada por concepçóes científicas fundamentadas na sociologia funcionalista, na psicologia do desenvolvimento, no pragmatismo e no behaviorismo, articulando-se, ainda, com a teoria do capital humano. Os discursos pedagógicos e os lugares comuns que induzem a propósito da educabilidade humana, a imprescindibilidade da sua educação escolar e a omnipotência do adulto face à criança enformam também a narrativa, na sua dimensão ideológica, realçando-se a expressão de uma heterogeneidade de discursos pedagógicos que contribuem, no entanto, para situar a infância no núcleo da esperança ontológica de construção de um mundo melhor.

A narrativa da "infância com lugar próprio" caracteriza-se pela consideração da sua alteridade e uma compreensão da infância em função do que ela é e não relativamente ao que se pretende que venha a ser, descentrando-a do controlo do adulto e configurando um lugar social que lhe é próprio e no qual ela é a entidade principal. A psicanálise e o pragmatismo contribuem para a fundamentação científica da narrativa, e os discursos pedagógicos inovadores, designadamente os que indiciam representaçôes sobre uma atitude pedagógica não directiva, constituem a sua dimensão ideológica, caracterizando-se a dimensão ética pelo comprometimento de possibilitar às crianças afirmar a sua subjectividade em condições de liberdade. 
A narrativa da "infância idílica” configura um lugar mágico para a infância e atribui-lhe uma dimensão simbólica na ontologia humana que a idealiza como a idade da fantasia, da sensibilidade, da ternura e do afecto, da criatividade e da confiança no mundo e na humanidade. Essa idealização funda-se na consideração de que, em cada um de nós, se mantém essa dimensão fantástica e angélica que pode a qualquer momento ser resgatada e que representa a ontologia pura do adulto, que se fundamenta nos contributos conceptuais da psicanálise. As ideologias pedagógicas derivadas do pensamento de Rousseau e que induzem a identificar na infância as qualidades que supostamente a vida social retirou ao adulto informam também esta narrativa, que origina um comprometimento ético paradoxal, uma vez que, se por um lado se rege por princípios de preservação da natureza angélica da infância, pelo outro produz interpretaçôes contraditórias sobre as crianças, dicotomizando-as entre a verdadeira infância e a sua subversão, que se exprime na ideia de criança perversa.

A narrativa da "infância produtiva" relaciona-se com os discursos implicados na configuração dos ofícios de aluno e fundamenta-se em termos conceptuais nas perspectivas construtivistas da psicologia e nas concepções da teoria do currículo e, em termos ideológicos, na ideia de criança activa, na pedagogia do esforço e segundo uma racionalidade técnica. A ideia de ocupação utilitária da infância encontra-se no cerne da narrativa, desvalorizando-se a acção lúdica e desinteressada das crianças e integrando o lugar social da infância numa lógica da produtividade que estabelece relaçóes com racionalidades do mundo laboral e económico e com racionalidades políticas oriundas da tecnocracia, da democracia ou do socialismo.

A narrativa de "a infância em risco" fala-nos de um tempo actual e problemático para a infância e implica-se numa interdiscursividade que cria novas representaçôes sociais sobre o lugar da instituição escolar na gestão da crise social e das suas implicações para a infância. Nessa narrativa o lugar social da infância é o lugar da incerteza, da exclusão, da sobrevivência e da submissão a maus-tratos e a condiçôes de vida que não consideram a humanidade específica das crianças.

As narrativas da infância exprimem-se nos campos discursivos de modo articulado com narrativas específicas sobre a profissionalidade docente: "profissional mediador", "profissional especialista", "profissional em crise", "profissional pedagogo" e "profissional em construção"; e sobre a educação escolar: "educação tradicional", "educação democrática", "educação situada" e "educação em crise". A inscrição dessa articulação em determinados tipos de formação inicial e formas de discurso levou-nos a mapeá-la para compreender as especificidades da sua expressão em diferentes momentos do período em que focalizámos a análise. Esse mapeamento permitiu consolidar a percepção de que algumas narrativas se exprimiam preferencialmente em determinados tipos de formação ou formas de discurso, mas sobretudo permitiu compreender que elas constituem recursos 
discursivos disponíveis ao longo de todo o período e que sofrem alterações em função das articulações que estabelecem.

\section{O mapeamento social das narrativas da infância}

O mapeamento social das narrativas da infância, sendo a dimensão morfológica do estudo, constituiu o núcleo conceptual da interpretação. Ele realizou-se através da definição de campos sociais que constituíram as coordenadas da cartografia. A definição desses campos fundamentou-se nas dimensões que formam as narrativas da infância e considerou como determinantes os campos da ciência, da cultura, da ideologia, da ética e da política. Cada campo não se define, no entanto, por fronteiras fechadas, estabelecendo relações intertransformantes com os restantes, que se traduzem em configurações particulares em cada narrativa.

No campo da ciência, a psicologia e a sociologia dominam a referencialização das narrativas, com hegemonia para o construtivismo no caso da primeira e para o funcionalismo no caso da segunda, constituindo a teoria social crítica uma subcoordenada periférica do mapeamento. O panorama conceptual das narrativas situa-nos na metanarrativa científica da modernidade e, por isso, podemos referir que a psicologia e a sociologia legitimadas pelo paradigma da ciência moderna são dominantes na narração da infância em formação inicial de professores. Mas esses discursos surgem recontextualizados em termos ontológicos e públicos nos campos discursivos dos relatórios de estágio e das narrativas biográficas, que denunciam uma tendência para conceber a infância numa perspectiva híbrida de natureza e cultura, fundamentada em práticas de tradução que ressignificam os discursos científicos mestiçando-os com uma hermenêutica do social.

No campo da política realça-se a coexistência da democracia, do socialismo e da tecnocracia. No entanto, o paradigma da democracia revela-se o de maior penetração e extensão, exprimindo-se em todos os tipos de formação e formas de discurso. Mas os discursos sobre a democracia não são consensuais e homogéneos, sofrendo metamorfoses ao longo do período analisado que se relacionam com a sua implicação nos campos da ideologia e da ética. Inscritos na dimensão da subjectivação escolar e dos ofícios de aluno, os discursos sobre a democracia revelam a sua implicação na administração e regulação da infância na instituição escolar e manifestam-se divergentes em função dos lugares onde se formam e das concepções ideológicas e éticas que os matriciam. Assim, a democracia não constitui nas narrativas da infância um modelo social percebido como unitário, mas suscita diferentes representaçôes sobre o que é justo e o que é de direito quanto ao lugar social da infância e à sua implicação no seu governo. A democracia constitui uma dimensão paradoxal da educação escolar da infância, e a impossibilidade da sua expressão nos quotidianos escolares permite realçar que ela constitui sobretudo uma narrativa "de salvação" e de gestão da crise da instituição escolar, com uma função mais simbólica do que real. 
O campo da cultura define-se por domínios que se têm revelado ética e ontologicamente incompatíveis e, por isso, ele caracteriza-se por um espectro intrinsecamente contraditório que considera simultaneamente o universalismo e o localismo, integrando ainda o multiculturalismo, o presenteísmo e o simbolismo. A cultura universalista que se identifica é uma cultura formal baseada em substâncias convencionais; que desvaloriza o corpo relativamente à cognição; que considera o tempo na sua dimensão monocronológica e o separa do espaço; e que minimiza a dimensão estética. A cultura localista reabilita o comunitário, a intersubjectividade, a expressividade e a policronologia do tempo. Na matriz do universalismo identificamos o paradigma cultural da modernidade e na do localismo a convergência de diferentes racionalidades e formas culturais mais próximas da prémodernidade ou da modernidade tardia. O multiculturalismo identifica-se, sobretudo, no currículo formal ou nos discursos nele implicados dos cursos mais recentes, mas sem impacto nas formas culturais narradas pelas professoras ou pelas estagiárias, o que nos permite considerar que os discursos que o configuram constituem mais uma ideologia do que a expressão de uma realidade cultural escolar.

A imbricação da dimensão cultural no mundo da vida indicia-nos sobre os processos de entendimento, de coordenação da acção e de socialização implicados na reinstitucionalização escolar da infância narrada em formação inicial, e esta revela-se contraditória e gerada por racionalidades culturais divergentes que tornam incerto o seu sentido. A narração da socialização da infância enuncia-a como caracterizada por dimensões contingentes ou fundamentadas em racionalidades culturais deslegitimadas ou que ainda não têm sustentabilidade institucional e social.

$\mathrm{O}$ saber escolar e as racionalidades que fundamentam as formas da sua aprendizagem situam-se no cerne da problemática da cultura escolar e revelam-se heterogéneas nas diferentes narrativas, sobretudo no que diz respeito às relaçōes das crianças com o saber. A relação com o saber não é meramente epistémica e cognitiva; ela constitui uma relação social e uma relação identitária (CHARLOT, 1997) que, no entanto, não são consideradas nos discursos que formam as narrativas da infância, que não nos indiciam a percepção sobre o impacto das formas culturais, designadamente as que se referem à aprendizagem escolar, na construção da identidade das crianças e das suas relações com o mundo, narrando-as como uma dimensão individual e psicológica.

O campo da ideologia define-se em torno de ideologias dominantes - o racionalismo, o humanismo, o industrialismo, a igualdade de oportunidades e a ideologia do esforço e de ideologias marginais - a não-directividade, o pedocentrismo e a inclusão - na narração da infância. As ideologias constituem entidades simbólicas mediadoras na constituição das sociabilidades e das estruturas sociais (RICOEUR, 1991) e também se relacionam com a linguagem e a comunicação que se desenvolvem na instituição de formas de vida (HABERMAS, 1993). Nesse sentido as ideologias que identificámos falam-nos da reinstitucionalização da infância e das transformações na instituição escolar. 
As narrativas da infância dão-nos conta de ideologias contraditórias e que configuram a formação de um super self: cosmopolita, auto-responsável, esforçado, integrado e humanista, mas também sensível, criativo, individualista e hedonista, indiciando uma subjectivação escolar ambiciosa e intrinsecamente incompatível que coloca a infância num lugar social virtual de difícil concretização. No entanto, as diferentes formas de discurso que constituem os campos discursivos revelam uma desarticulação na narração das ideologias, que origina uma rede difusa de significaçôes sobre a infância e sobre a instituição escolar.

As significações sobre a infância que se induzem das ideologias da sua narração situamna tanto no domínio de projectos sociais específicos, quanto no da sua subjectividade, cultura e natureza particulares. O paradigma da modernidade pretendeu estabelecer uma ruptura entre essas dimensões, mas nos discursos dos relatórios de estágio e das narrativas biográficas elas surgem profundamente imbricadas, e os dispositivos de gestão institucional escolar da infância, designadamente os que se identificam no currículo formal da formação inicial, não possibilitam gerir essa hibridez, colocando nas "mãos» das professoras e das estagiárias o trabalho de transformação das representações cognitivas sobre o lugar social da infância e dos quadros de significação sobre as crianças. Por isso, essa transformação só pode revelar-se contingente e subjectiva, dificultando a sua estabilização e originando práticas escolares aleatórias.

O campo da ética revela-se informado, simultaneamente, por significações inscritas nos domínios público - a subjectivação, o trabalho e a cidadania - e privado - o afecto e o cuidado - ou pela sua mestiçagem - a liberdade. As primeiras emergem nos campos discursivos transfiguradas em discursos morais, o que delega a sua dimensão ética no comprometimento das professoras que pode ou não verificar-se, identificando-se ainda uma diversidade de perspectivas sobre a subjectivação escolar nos diferentes tipos de formação. Essa diversidade está implicada na dicotomização moderna entre o indivíduo e a sociedade, que parece não encontrar respostas para a sua crise no contexto da narração da infância em formação inicial de professores.

Os discursos analisados evidenciam uma ambiguidade entre a ética e a moral na educação escolar da infância, que está implicada no paradoxo estruturante da modernidade traduzido na sua conceptualização bipolarizada entre a emancipação e a regulação. A ética do cuidado, do afecto e da liberdade implicam-se no comprometimento ético na educação escolar da infância. No entanto, o insucesso escolar, que se deveria situar no seu cerne, surge narrado de forma dissociada dos discursos éticos, parecendo que estes constituem mais uma retórica que ilude os reais efeitos do insucesso escolar na vida das crianças e as responsabilidades que sobre ele recaem nos professores. A ética da liberdade póe em causa a polaridade adulto/criança e com ela um conjunto de outras polaridades que têm caracterizado as sociedades ocidentais, designadamente as polaridades maturidade/ 
imaturidade, homem/mulher, superior/inferior, que resultam de relaçōes de força inerentes aos processos de civilização (IMBERT, 1987) e que implicam o exercício da «violência» que se exerce, também, na instituição escolar. É essa violência que se coloca em causa na ética da liberdade, que apenas emerge nos discursos do currículo formal do curso de magistério primário do $1^{\circ}$ subtipo, reaparecendo actualmente em algumas das narrativas biográficas.

\section{TÓPICOS PARA UMA REFLEXÃO PROSPECTIVA}

A incapacidade da ciência moderna em produzir conhecimento que permita conhecer a infância na sua hibridez associada à sua hegemonia na formação inicial de professores coloca problemas aos professores em compreender e gerir as relações quotidianas que desenvolvem com as crianças em contexto escolar.

As crianças realizam-se como seres humanos de forma alheada dos saberes que os adultos sobre elas produzem e subvertem a pretensa racionalização dos seus mundos da vida, provocando instabilidade na identidade profissional dos professores e perturbando a sua profissionalidade.

Os professores oscilam entre os saberes científicos veiculados na formação inicial e os saberes que resultam das relações concretas que desenvolvem com as crianças fora e dentro da escola, que se revelam dissonantes.

Se outrora o professor era um mediador entre a sociedade e a infância, ele agora é produtor de justificações e de significaçōes sobre a educação escolar e sobre a infância, o que coloca novos desafios na sua profissionalização.

A ciência já não pode ditar as normas para a acção, mas tem que se fazer escutando, compreendendo e objectivando os saberes, as representaçóes e as significaçôes que se produzem nos contextos da acção educativa.

O trabalho de mediação entre diferentes formas de saber e entre os microactores e os macroactores torna-se incontornável; e a reflexão sobre o impacto da educação escolar na vida das crianças e o lugar que a formação inicial aí ocupa evidencia-se como um imperativo ético.

\section{Notas}

1. Desde Abril de 1974 a formação inicial de professores do $1^{\circ} \mathrm{CEB}$ sofreu mudanças profundas no seu estatuto académico e na sua organização, designadamente: nas condições de acesso - do $5^{\circ}$ ano (actual $9^{\circ}$ ano de escolaridade) para o $7^{\circ}$ ano (actual $11^{\circ}$ ano) e para o $12^{\circ}$ ano; no número de anos de formação - de 2 para 3 anos, posteriormente para 4 anos e actualmente 3anos +2 anos; no nível de qualificação - de ensino normal para ensino superior de nível de bacharelato (LBSE - Lei no 46/86 de 14 de Outubro), para nível de licenciatura (Lei no 115/97 de 19 de Setembro), para nível de 
mestrado (Decreto-Lei no 43/07 de 22 de Fevereiro); na ruptura com a tutela exclusiva por parte do estado - criação e expansão das instituições de ensino particular de formação de professores.

2. Narrativas da profissionalidade docente: "profissional mediador", "profissional especialista", "profissional pedagogo", "profissional em crise" e "profissional em construção". Narrativas da educação escolar: "educação tradicional”, "educação democrática”, "educação em crise” e "educação situada”.

\section{Referências}

ARIÈS, Philippe. História social da criança e da família. Rio de Janeiro: Guanabara, 1978.

BAKHTIN, Mikhail. Marxismo e filosofia da linguagem. São Paulo: Hucitec, (Voloshinov, V. N. 1929), 1992.

CHARLOT, Bernard. Da relação com o saber. Elementos para uma teoria. Porto Alegre: Artmed, 1997.

DE BRUYNE, Paul; HERMAN, Jacques; DE SCHOUTHEETE, Marc. Dinâmica da pesquisa em ciências sociais. Rio de Janeiro: Francisco Alves, 1991.

DUBET, François. Le déclin de l'institution. Paris: Seuil, 2002.

FOUCAULT, Michel. A arqueologia do saber. Rio de Janeiro: Forense Universitária, (obra original publicada em 1969), 2004.

HABERMAS, Jürgen. Técnica e ciência como «ideologia». Lisboa: Edições 70, (obra original publicada em 1968), 1993.

Racionalidade e comunicação. Lisboa: Edições 70, 2002.

IMBERT, Francis. La question de l'éthique dans le champ éducatif. Pour une praxis pédagogique II. Vigneux: Matrice, 1987.

JENKS, Chris. Constituindo a criança. Educação, Sociedade e Culturas, Porto: Afrontamento, v. 17, p. 185-216, 2002.

LESSARD-HEBERT, Michelle; GOYETTE, Gabriel; BOUTIN, Gérald. Investigação qualitativa. Fundamentos e práticas. Lisboa: Instituto Piaget, 1994.

PEREIRA, Fátima. Transformação educativa e formação contínua de professores: os equívocos e as possibilidades. Lisboa: Ministério da Educação - IIE, col. Políticas da Educação, 2001.

Idealizar a vida, gerir o presente e projectar o futuro: o governo da infância nos discursos em formação inicial de professores. 2007. f. Tese (doutorado). Faculdade de Psicologia e Ciências da Educação, Universidade do Porto, Portugal.

RAYOU, Patrick. La grande école. Approche sociologique des compétences enfantines. Paris: Presses Universitaires de France, 1999.

RICOEUR, Paul. Ideologia e utopia. Lisboa: Edições 70, (obra original publicada em 1973), 1991.

SARMENTO, Manuel Jacinto. A globalização e a infância: impactos na condição social e na escolaridade. In: O particular e o global no virar do milénio. Cruzar saberes em educação - Actas do 5० Congresso da Sociedade Portuguesa de Ciências da Educação. Lisboa: Colibri/ Sociedade Portuguesa de Ciências da Educação, 2002, p. 691-698.

SCRATON, Phil (Ed.). Childhood in 'crisis'? Londres: Routledge, 1997. 


\section{Speeches on Childhood In Early Teacher Training - Portugal In The Last Decades Abstract}

A study carried out as part of the work for a PhD thesis in Education Sciences whose purpose was to find out about and understand the conceptions on childhood that are expressed in or related to early teacher training for the 1st cycle of basic education (CEB) in Portugal since April 1974. A multirreferencial problematic was built up around the discursive management of the crisis of modern childhood, of teacher professionalism and the school institution in late modernity. The morphological dimension of the study consisted of the configuration and social mapping of narratives on childhood which were identified in the interpretation of the discourse fields produced in the analysis. Moreover, narratives on teacher professionalism and school education have been identified with which narratives on childhood are articulated in a particular form. The paper briefly presents the problematic, the methodological dimension and some of the results of the study, highlighting those relative to the transformations verified in the speeches during the period in analysis, and the social mapping of childhood narratives.

Keywords: Curriculum. 1st cycle of basic education. Early teacher training. Narrative. Social mapping.

\section{Discours sur l'enfance dans la formation initiale de maîtres - Portugal dans les dernières décennies} Résumé

Une étude réalisée comme partie du travail d'une thèse de doctorat en Sciences de l'Éducation qui a prétendu connaître et comprendre les conceptions sur l'enfance qui s'expriment dans, ou font une relation avec la formation initiale de maîtres du ler cycle de l'enseignement de base - CEB - au Portugal depuis 1974. Il s'est configurée une problématisation multirréférentielle autour de la gestion discursive de la crise de l'enfance moderne, de la professionnalité des mâtres et de l'institution scolaire en temps de modernité tardive. La dimension morphologique de l'étude se constitue par la configuration et l'inventaire social de narratives sur l'enfance qui se sont identifiées dans l'interprétation des champs discursifs produits dans l'analyse. Ont été identifiées, encore, des narratives sur la professionnalité des maîtres et sur l'éducation scolaire avec lesquelles les narratives sur l'enfance s'articulent de forme particulière. La problématique, la dimension méthodologique et quelques résultats de l'étude sont présentés succinctement, rehaussant ceux qui se réferent aux transformations vérifiées dans les discours, dans la période de temps en analyse, et à l'inventaire social des narratives de l'enfance.

Mots clefs : Curriculum. ler cycle de l'enseignement de base. Formation initiale de maîtres. Narrative. Inventaire social.

\section{Discursos acerca de la infancia en la formación inicial de profesores - Portugal en las últimas décadas Resumen}

Un estudio realizado en el ámbito de una tesis de doctoramiento en ciências de la educación que intentó conocer y comprender las concepciones acerca de la infancia que se exprimen o se relacionan con la formación inicial de profesores del $1^{\circ}$ ciclo de la enseñanza primaria (CEB), en Portugal desde abril de 1974. Se configuró una problematización multirreferencial en torno a la gestión discusiva de la crisis de la infancia moderna, de la profisionalidad docente y de la instituición escolar en tiempos de modernidad tardía. La dimensión morfológica del estudio se constituyó por la configuración y el mapeamiento social de narrativas sobre la infancia que se identificaron en la interpretación de los campos discursivos producidos en el analisis. Se identificaron aún narrativas sobre la profissionalidad docente y sobre la educación escolar, con las cuales las narrativas acerca de la infancia se articulan de forma particular. Se presenta sucintamente la problemática, la dimensión metodológica y algunos de los resultados del estudio, realizándose los que están relacionados a las transformaciónes verificadas en los discursos, en el periodo en análisis, y al mapeamiento social de las narrativas de la infancia.

Palabras-clave: Currículo. $1^{\circ}$ ciclo de la enseñanza primaria. Formación inicial de profesores. Narrativa. Mapeamiento social.

Recebido: 14.12 .2007

Aceito: 17.03 .2008 


\title{
CONSULTORES AD HOC 2007
}

\author{
Gilberto dos Santos Prado \\ (Universidade de São Paulo - SP) \\ Gilberto Lacerda dos Santos \\ (Universidade de Brasilia - DF)
}

Gilda Helena Bernardino de Campos

(Pontificia Universidade Católica do Rio de Janeiro - RJ)

Iduina Edite Mont'Alverne Braun Chaves

(Universidade Federal Fluminense - RJ)

José Armando Valente

(Universidade Estadual de Campinas - SP)

Maria Constança Peres Pissarra

(Pontifícia Universidade Católica de São Paulo-SP)

Maria Helena Souza Patto

(Universidade de São Paulo - SP)

Sônia Regina Fiorim Enumo

(Universidade Federal do Espírito Santo - ES)

Tania Mara Galli Fonseca

(Universidade Federal do Rio Grande do Sul-RS)

Tereza Cristina Cavalcanti Ferreira de Araujo

(Universidade de Brasilia - DF) 